doi:

\title{
Search for streptomycetes with antagonistic activity to the aggressive Fusarium sp. strain AC
} Tovstik E.V. ${ }^{1}$, Bakulina A.V. ${ }^{2}$

${ }^{1}$ Vyatka State University, Kirov, Russia; ${ }^{2}$ Federal Agricultural Research Center of North-East named N.V. Rudnitsky, Kirov, Russia

E-mail: drugaeann1@ rambler.ru

Key message. The antagonistic activity of 126 Streptomyces strains against the fungus Fusarium sp. AC was studied. The greatest extent of mycelium growth was inhibited by S. geldanamicininus $3 K 9$, which produces validamycin $A$.

Keywords: Fusarium proliferatum, identification, Streptomyces, phytopatogens biocontrol, antagonistic activity

Representatives of the genus Streptomyces are known for their great potential for the synthesis of secondary metabolites, including those with antifungal activity. Every year, significant damage to the yield and quality of various crops grain is caused by Fusarium fungi, which can be controlled with streptomycetes. The aim of this research was to identification a phytopathogenic fungus strain isolated from the soil in the Kirov region and to search for streptomycetes that have antagonistic activity to it. According to the nucleotide sequence of the ITS site, the strain AC was assigned to the genus Fusarium, and its closest relatives found by the BLAST are the species: F. proliferatum, F. fujikuroi, and F. verticillioides. The cultural and morphological characteristics of the studied strain corresponded to the description of $F$. proliferatum (cottonlike colonies, air mycelium white, fast-growing, the reverse side colorless, hyphae colorless, septic, simple conidiophores). It is known that this species, detected in our country mainly in the southern region, is characterized by the formation of a dangerous mycotoxin - fumosin (Gagkayeva et al., 2011). Screening of antagonistically active cultures was performed among 126 Streptomyces strains isolated from soil and rhizosphere (80 and 46 strains, respectively). The ability to suppress the growth of fungal mycelium in pure cultures was found only in three soil Streptomyces strains (inhibition zones 16, 22, 24 $\mathrm{mm}$ ), and among rhizospheric - none. The most active strain was S. geldanamicininus $3 \mathrm{~K} 9$, for which the ability to synthesize an antifungal antibiotic (validamycin A) was previously detected (Tovstik et al., 2019). Thus, the data obtained by us confirm the need to study the biocontrol potential of streptomycetes in order to use them in conducting environmentally safe agriculture.

\section{Поиск стрептомицетов-антагонистов к агрессивному штамму Fusarium sp. AC} Товстик Е.B. ${ }^{1}$, Бакулина A.B. ${ }^{2}$

${ }^{1}$ Вятский государственный университет, Киров, Россия; ${ }^{2}$ Федеральный аграрный научный центр Северо-Востока имени Н.В. Рудницкого, Киров, Россия

Аннотация. Изучена антагонистическая активность 126 штамлов стрептомицетов в отношении гриба Fияагіит sp. AC. В наибольшей степени рост мицелия ингибировал S. geldanamicininus $3 K 9$, продуцируюший валидамицин A. Ключевые слова: Fusarium proliferatum, идентификация, Streptomyсеs, биоконтроль фитопатогенов, антагонистическая активность

Представители рода Streptomyces известны огромным потенциалом в отношении синтеза вторичных метаболитов, в том числе обладающих антифунгальной активностью. Ежегодно значительный ущерб урожаю и качеству зерна различных культур наносят заболевания, вызванные грибами рода Fusarium, для борьбы с которыми могут быть использованы биопрепараты на основе стрептомицетов. Целью настоящей работы была идентификация выделенного нами из почвы на территории Кировской области фитопатогенного гриба штамма АС и поиск стрептомицетов, обладающих к нему антагонистической активностью. По нуклеотидной последовательности участка ITS штамм AC был отнесен к роду Fusarium, а его ближайшие родственники, найденные сервисом BLAST, - виды: F. proliferatum, F. fujikuroi, F. verticillioides. Культурально-морфологические признаки исследуемого штамма соответствовали описанию F. proliferatum (колонии ватообразные, воздушный мицелий белый, быстрорастущий, обратная сторона бесцветная, гифы бесцветные, септированные, конидиеносцы простые). Известно, что для этого вида, выявляемого в нашей стране преимущественно в Южном регионе, характерно образование опасного микотоксина - фумозина (Гагкаева и др., 2011). Скрининг антагонистически активных штаммов проводился среди 126 культур стрептомицетов, выделенных из почвы и ризосферы (80 и 46 штаммов соответственно). Способность подавлять рост мицелия гриба в чистых культурах была установлена только у трех почвенных штаммов Streptomyces sp. (зоны ингибирования 16, 22, 24 мм), а среди ризосферных - ни у одного. Наиболее активным оказался штамм S. geldanamicininus 3К9, для которого ранее была обнаружена способность к синтезу противогрибкового антибиотика (валидамицина А) (Товстик и др., 2019). Таким образом, полученные нами данные подтверждают необходимость изучения биоконтрольного потенциала стрептомицетов с целью их использования при ведении экологически безопасного сельского хозяйства. 